\title{
Dyadic Emotion Regulation in Women with Borderline Personality Disorder
}

\author{
Annemarie Miano $0^{1,2} \cdot$ Sven Barnow ${ }^{1} \cdot$ Stina Wagner ${ }^{1} \cdot$ Stefan Roepke ${ }^{2,4} \cdot$ Isabel Dziobek $^{2,3}$
}

Accepted: 8 January 2021 / Published online: 20 February 2021

(c) The Author(s) 2021

\begin{abstract}
Background Emotion regulation (ER) and interpersonal dysfunction constitute key features of borderline personality disorder (BPD). Here, we tested if females with BPD show impairments in dyadic ER, that is in their support seeking and creation of closeness. We investigated if women with BPD might over-rely on their male partner by excessive support seeking and establishing of closeness, during conversations with personally and relationship-threatening topics.

Methods Thirty couples in which the women were diagnosed with BPD and 34 healthy control (HC) couples were videotaped while discussing neutral, personally threatening, and relationship-threatening topics. Support seeking was rated by three independent raters, using a naïve observer method. The creation of closeness was rated using a continuous video-rating. Perceived emotions were assessed using self-report after each conversation.

Results Women with BPD engaged in more support seeking than HC women, especially in more negative behaviors to elicit support, they created less closeness to their partner than HCs and reported a greater decline of positive emotions in both threatening conditions. Women with BPD displayed more fluctuations than controls between creating closeness and distance in the personally-threatening situation. They reported a larger increase in negative emotions after the relationship threatening conversation compared to female HC.

Conclusions The present study indicates an increased demand of dyadic ER in BPD. Increased negative support seeking and less creation of closeness to the partner might reflect ineffective strategies to actually receive support from the partner.
\end{abstract}

Keywords Dyadic emotion regulation · Support seeking · Dyadic coping $\cdot$ Borderline personality disorder $\cdot$ Couples

Borderline personality disorder (BPD) is characterized by severe and persistent interpersonal, behavioral, and emotional dysfunction (American Psychiatrc Association [APA] 2013). Emotion dysregulation (Daros and Williams 2019;

Stefan Roepke and Isabel Dziobek authors have contributed equally to this work.

Annemarie Miano

Annemarie.Miano@psychologie.uni-heidelberg.de

1 Department of Clinical Psychology and Psychotherapy, Ruprecht-Karls-University, Heidelberg, Germany

2 Research Cluster Languages of Emotion, Freie Universität, Berlin, Germany

3 Berlin School of Mind and Brain, Institute of Psychology, Humboldt-Universität Zu Berlin, Berlin, Germany

4 Department of Psychiatry and Psychotherapy, Charité - Universitätsmedizin Berlin, Campus Benjamin Franklin, Berlin, Germany
Sauer et al. 2016) and disturbances in interpersonal relationships (Beeney et al. 2018; Miano et al. 2020) are diagnostic features of BPD (APA 2013). Until now, little was known about how individuals with BPD regulate their emotions in a dyadic context. Here, we investigated dyadic emotion regulation, i.e. support seeking, support providing and creating of closeness and distance in females with BPD and their male romantic partners.

Current developmental models of BPD either postulate emotional dysregulation and impulsivity (Lieb et al. 2004; Linehan 1993) or interpersonal dysfunction and sensitivity at the core of BPD (Barnow et al. 2009; Fonagy and Bateman 2008; Gunderson 2007; Levy 2005; Stanley and Siever 2010). Individuals with BPD experience heightened affective instability with sudden and large changes from positive to negative mood states (Ebner-Priemer et al. 2007; Houben et al. 2016) and faster emotional reactivity to triggers (Donegan et al. 2003; Ebner-Priemer et al. 2005), especially interpersonal ones (Houben et al. 2018). The ability 
to adaptively regulate emotions was shown to be disturbed in BPD (Barnow et al. 2012; Conklin et al. 2006) and is covered in one of the core modules of dialectical behavioral therapy, an effective treatment for BPD (Goodman et al. 2014; Linehan 1993). Individuals with BPD are often concerned with abandonment and rejection (Berenson et al. 2016; Staebler et al. 2011) and struggle with interpersonal relationship disturbances, reflected in little relationship stability and poor quality (Bouchard et al. 2009; Miano et al. 2020). Both symptom clusters, were shown to be of high diagnostic value, emotion dysregulation in terms of the criteria with the highest sensitivity (Zimmerman et al. 2017) and interpersonal dysfunction in predicting BPD diagnoses longitudinally (Grilo et al. 2007). Therefore, the understanding of both relationship dysfunction and ER difficulties, and how they might possibly exacerbate one another, are of particular importance to the study of BPD.

Emotion regulation (ER) refers to the conscious or unconscious processes by which individuals influence which emotions they have, when they have them, and how they experience and express these emotions (Gross 1998). Emotion dysregulation can manifest in a lack of awareness and acceptance of emotions, as well as in failures to have access to or engage in ER strategies (Gratz and Roemer 2008). ER processes can take place in an individual itself or - in form of dyadic ER - between two individuals, where emotions are regulated with the help of another person during interactions (Hofmann 2014; Zaki and Williams 2013). In fact, 98\% of ER may take place in social contexts (Gross et al. 2006). During adulthood, the romantic partner is among the most important source and target of dyadic ER (Coan et al. 2006; Dakof and Taylor 1990; Julien and Markman 1991). Dyadic ER can be asymmetric, that is person A regulates his or her emotions with the help of person $\mathrm{B}$, or symmetrical, that is person A and B regulate their emotions simultaneously with each other. Here, we will focus on asymmetric ER.

Seeking and providing of support (Pasch 2004; Bradbury 2004; Simpson et al. 2002; Grich 2002) and creating closeness or distance (Bolwby 1969; Mikulincer et al. 2002) are two concepts of dyadic ER, that allow an assessment of dyadic ER on a behavioral level and at the same time measure asymmetric dyadic ER. When individuals experience negative emotions in reaction to stressful or threatening events, distress is expressed and people seek support and create closeness in response to this (Mikulincer et al. 2002; Simpson et al. 1992), preferably towards their partner when available (Collins and Feeney 2004). The support seeker's expression of distress in turn should elicit caregiving and supportive behavior from the support provider. Depending on the extent to which the support seeker perceives the behavior from the support provider as supportive, he or she should experience immediate short-term benefits in wellbeing, such as reduced anxiety, improved mood and greater perceived ability to cope (Collins and Feeney 2000; Collins and Ford 2010). Individuals that receive support or feel confident, that support will be provided when needed, are more successful at coping with stressful, negative life events and have long-term benefits in health and psychological wellbeing (Gurung et al. 1997; Pierce et al. 1996).

Several studies indicate that individuals with BPD report significantly higher levels of dependency and clinginess in interpersonal relationships (Beck et al. 2004; Perry and Klerman 1978; Westen et al. 1992) as well as a higher level of neediness (Cogswell and Alloy 2006; Levy et al. 2007) than non-BPD samples. BPD traits were found to be associated with more reassurance seeking (Dixon-Gordon et al. 2018). Moreover, a comorbidity between BPD and dependent personality disorder is often reported (For a review see Bornstein et al. 2010). The inability to effectively regulate emotions was suggested to be compensated with excessively seeking support from other people (Linehan 1993). This reaching out, often apparent in behaviors like emotional clinging and demanding, however, might stress and overstrain a romantic relationship, causing disturbances and dysfunctions (Hall and Baym 2012), which is a hallmark of BPD.

Individuals vary in their ability to seek support (Pasch 2004) and there are positive and negative ways of support seeking (Pasch 2004; Verhofstadt et al. 2013). Positive ways refer to behaviors that elicit compassion and empathy in the support provider without imposing pressure upon him or her. Negative ways of seeking support describe behaviors that elicit negative emotions in the support provider and increase pressure. Individuals with BPD and to a lesser extent their partner, were shown to exhibit a variety of problematic communication styles (Beeney et al. 2019; Bouchard et al. 2009; Fruzzetti 2006; Fruzzetti and Payne 2015; Miano et al. 2017c) like demanding, criticizing, blaming and nagging, which can be used to seek support in a negative way (Pasch 2004). To our knowledge, no previous study has examined dyadic ER in terms of support seeking or the creation of closeness and distance in females with BPD and their male romantic partners. One study has investigated support providing and its association with BPD symptomatology. In this study Lavner et al. (2015) examined the association between BPD symptoms and newlyweds' observed communication patterns, partner characteristics and longitudinal marital outcomes. Couples engaged in two 10 min conversations, in each of which one randomly selected partner was told to talk about an issue he/she would like to change about himself/herself. The other partner was told to respond naturally, as he/she would if this issue came up between the couple. Afterwards trained observers were instructed to code the supportiveness of the responder's behaviors. The results showed that higher levels of BPD symptoms were associated 
with more negative skills during the support provision task for both, husbands and wives.

In terms of the creation of closeness, to the authors' knowledge, there is no research as to how much closeness individuals with BPD do in fact establish in times of stress and threats. Only studies on preferred interpersonal space exist, without focusing on threat or stress. Reduced preferred interpersonal closeness in a stop-distance paradigm with an unknown confederate was shown for participants with BPD (Fineberg et al. 2018). That is, participants with BPD indicated that an approaching confederate had stepped into their personal space earlier then HCs. Also in a paper-pencil version, female with BPD indicated to prefer bigger personal space around them (Schienle et al. 2015).

The present study investigated dyadic ER, i.e., support seeking and the establishment of closeness in BPD in reaction to different emotional stressors, i.e., conversations on personally and relationship-threatening topics with their own romantic partner. Based on prior research suggesting that individuals with BPD over-rely on others (i.e., Beck, Freeman, Davis, \& Associates), we expected (1) females with BPD to seek more support from and create more closeness to their partners. Considering their negative communication styles (i.e., Bouchard et al. 2009), we further presumed (2) females with BPD would seek support in a more negative and less positive way than women in the HC sample. Due to their affective instability (Houben et al. 2016) we (3) also expected BPD participants to show more fluctuations between creating closeness and distance in threatening situations than HC. (4) In relationship-threatening situations, we expected these differences to be even more pronounced than in personally-threatening situations, as research on BPD indicates that BPD participants show more pronounced emotional reactivity when stimuli are BPD-relevant compared to generalized negative stimuli (Limberg et al. 2011). Finally, we (5) expected that these changes in dyadic ER would be reflected in participants reported negative and positive emotions after the conversations. That is, we expected females with BPD to have more negative and less positive emotions after the threatening conversations, compared to HCs.

\section{Methods}

\section{Participants}

Thirty-one heterosexual and unmarried couples in which the women were diagnosed with BPD, and $37 \mathrm{HC}$ couples participated in a couple communication study on social cognition and behavior in BPD (Miano et al. 2017a, b, c). Couples were together for at least three months. Exclusion criteria for $\mathrm{HC}$ couples included currently meeting full diagnostic criteria for one of the most common DSM-IV Axis-I or Axis-II psychiatric disorders. Exclusion criteria for BPD couples included one of them reporting a current manic or psychotic episode and one partner being in inpatient therapy. When a partner of the BPD couple met criteria for alcohol or substance dependence during the past 12 months, they had to be in remission for at least three months. Groups were matched on age and relationship length.

One HC couple wished to stop participating during the course of the experiment. Due to technical problems data from two HC couples and one BPD couple could also not be used. The final sample consisted of $30 \mathrm{BPD}$ and $34 \mathrm{HC}$ couples. Diagnostic characteristics and current axis I or II disorders of the BPD sample are summarized in Table 1 (also shown in Miano et al. 2017c). Recruiting was performed via internet-platforms, newspaper advertisement and postings in public areas. Additionally, BPD couples were recruited via psychiatric hospitals in Berlin and advertisement in private practices. Participants received financial reimbursement for participating. The study was approved by the local ethics commission.

\section{Procedure}

After inclusion criteria were verified, participants received detailed instructions and provided written informed consent. At home, participants completed an online survey containing demographic variables and the questionnaire on relationship quality. The procedure to measure dyadic ER consisted of two phases: the videotaping of the couple interactions and the assessment of support giving, support providing and creating closeness and distance by three independent raters.

\section{Video Recording}

Couples were videotaped while discussing three different topics for six minutes each. Each couple underwent all three conversations, which each lasted 6 min. Before each conversation, each couple member received an identical staple of cards with predefined answer options. They were told to privately choose the card that best describes their personal opinion or situation. In the first, which represented the neutral film condition, couples were asked to talk about their favorite film genre (i.e., Comedy, Science-fiction, Horror). After this condition, two conditions with negative connotations followed. In the fear condition participants were asked to discuss, which fear was most relevant to them during the past year (e.g. financial problems, fear of failure, being or becoming sick). In the separation condition couples were asked to talk about possible reasons that might lead to a break-up in their current relationship (e.g. different future visions, partner shows too little positive emotions, partner gives too little attention). After each participant made their private choice, couples were instructed to discuss which card 
Table 1 Item description of all dependent variables and inter-rater reliability

\begin{tabular}{|c|c|c|c|c|}
\hline & \multirow[b]{2}{*}{ Brief item description $^{\mathrm{a}}$} & \multicolumn{3}{|l|}{ ICC } \\
\hline & & Film & Fear & Separation \\
\hline $\begin{array}{l}\text { Creation of closeness and distance } \\
\text { OQCSSP }\end{array}$ & Continuous video rating with Video Mood & .58 & .72 & .76 \\
\hline Overall support seeking & "How much support does the person seek from his/her partner overall?" & .34 & .60 & 65 \\
\hline Positive support seeking & $\begin{array}{l}\text { "How much does the person seek support from his/her partner by eliciting empathy } \\
\text { and compassion in partner, without pressuring him/her?" }\end{array}$ & .36 & .61 & 62 \\
\hline Negative support seeking & $\begin{array}{l}\text { "How much does the person seek support from his/her partner by eliciting negative } \\
\text { emotions (e.g.: guilt) in his/her partner and pressuring him/her?" }\end{array}$ & .51 & 69 & .66 \\
\hline Overall support giving & "How much support does the person try to provide for his/her partner?" & .28 & .30 & .48 \\
\hline Positive support giving & $\begin{array}{l}\text { "How much does the person provide support by unburden his/her partner, reducing } \\
\text { negative emotions and increasing positive emotions" }\end{array}$ & .17 & .61 & .63 \\
\hline Negative support giving & $\begin{array}{l}\text { "How much does the person provide support, by giving unhelpful advices and that } \\
\text { possibly even intensify his/her negative emotions?" }\end{array}$ & .46 & .66 & .58 \\
\hline
\end{tabular}

OQCSSP observational questionnaire on couple's support seeking and providing, ICC intra-class-correlation of the ratings of three independent raters, ICCs smaller than 0.40 were excluded from further analyses

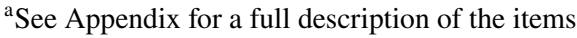

they chose, and to explain their choices. The experimenter left the room for the time of the conversations, gave a knocking sign $10 \mathrm{~s}$ before the end of the $6 \mathrm{~min}$ and then entered the room again. Following each conversation, couples went into separate rooms to fill in questionnaires including a threat manipulation check and a questionnaire on current emotions.

\section{Video Rating}

By making use of the naive observer method (Baucom et al. 2012) three independent observers rated creating closeness/distance as well as support seeking and support providing. This method is based on findings indicating that naive raters with no or only little observational training have an intuitive sense of communication in relationships. Ratings were made using the videotaped discussions. Observers were three female psychology students, who were not informed about the research question or about the existence of two groups (HC vs. BPD) and were therefore blind to the diagnostic couple group diagnostic status. Before rating the videos, raters were given a description and a list of behavioral anchors for each construct. Creating closeness/distance was rated continuously while watching the video using the program Video Mood (Miano et al. 2017a). Thereafter, support seeking and providing were rated once per person per conversation on a self-developed observation questionnaire, to which we will refer to in the following as Observational Questionnaire on Couple's Support Seeking and Providing (OQCSSP; see Appendix). All ratings were made for the male and the female part of each couple separately. We randomized the order of couples and whether to begin with the male or female, but not the order of the conditions because the conversations in the later conditions often referred back to conversations in former conditions.

\section{Questionnaires and Measurements}

\section{Diagnostic and Clinical Measurements}

DSM-IV Axis-I and II disorders were assessed using the Structured Clinical Interview for DSM-IV Axis-II Disorders (SCID-II; First, Spitzer et al. 1997) and the Mini International Neuropsychiatric Interview for DSM-IV Axis-I disorders (Sheehan et al. 1998). An evaluation of the interrater reliability of the BPD SCID-II diagnoses in our department revealed a good interrater reliability $(\kappa=0.82$; Ritter et al. 2014).

\section{Intelligence}

Fluid intelligence was measured using the subtest four of the German intelligence battery (Leistungsprüfungssystem (LPS); W. Horn 1983). This multidimensional and nonverbal measure of logical reasoning and fluid intelligence results in age-adapted IQ scores.

\section{Relationship Quality}

We measured the perceived relationship quality using the short form of the Partnership Questionnaire (PFB-K; Kliem et al. 2012). It is a 10-item questionnaire. Nine items can be scored ranging from 0 (never) to 3 (very often). Happiness with the relationship is an additional 1-item category, 
ranging from 0 (very unhappy) to 5 (very happy) and not reported here. The PFB-K has shown high internal validity and was normed in a German sample (Kliem et al. 2012). In the present study, Cronbach's alpha was good $(\alpha=0.79)$. Descriptive statistics of this questionnaire are also presented in a previous article (Miano et al. 2017b).

\section{Threat Manipulation Check}

To assess whether the manipulation worked as intended, in the manipulation check we asked the participants to rate their experienced threat on a scale from 1 (not at all) to 9 (a lot) for personal threat (two items; e.g., "How threatening was the conversation for you/your partner personally?") and relationship threat (five items; e.g. "How threatening was the conversation for your relationship?") after each conversation.

\section{Positive and Negative Emotions}

After each conversation, participants indicated on a LikertScale ranging from 1 (not at all) to 7 (very strong) how intensively they currently were experiencing 15 discrete emotions (adapted from Staebler et al. 2011). Emotions were averaged to either negative (anger, fear, sadness, hurt, loneliness, antipathy, contempt, despair and helpless) or positive (sympathy, satisfaction, pleasure, surprise, pride and joy) emotions. Cronbach's alpha was high for positive and negative emotions after all three conversations (all $\alpha>0.82$ ), except for positive emotions after the neutral film interaction, where it was low $(\alpha=0.54)$.

\section{Support Seeking and Support Providing}

In order to measure support seeking and support providing in a comprehensive and economic way, we developed the OQCSSP. We drew upon the idea of the Social Support Interaction Coding System (SSICS; Pasch 2004) which distinguishes between positive and negative ways of support seeking and support providing. The OQCSSP included four items derived from the SSICS: Positive support seeking (e.g., asking for help), negative support seeking (e.g., whining), positive support providing (e.g., giving helpful advice), and negative support providing (e.g., criticizing and blaming the support seeker for his or her problem). In addition to the four items derived from the SSICS, we added two items assessing support seeking/support providing in a more general and global way, by asking the observers to rate how intense a person overall seeks support/provides support. Each of the altogether nine items consisted of a brief description of the construct and a list of behavioral anchors consisting of the corresponding items of the SSICS described above (see Supplementary Material). We explicitly instructed the raters to not only rely on the descriptions and behavioral anchors but also on their intuitive understanding of the constructs. Ratings were made on an 8-point-Likert-scale ranging from 0 (not at all) to 7 (very strongly). Table 1 shows a list of items of the coding system and the constructs they are based on, as well as the inter-class-correlation between the three raters for each item. Ratings with insufficient inter-rater-reliabilities (ICC lower than 0.40) were excluded from further analysis.

\section{Creating Closeness/Distance}

Raters were asked to use their intuitive understanding of the concepts of creating closeness and distance. To ensure an activation of these concepts, and to increase the shared knowledge between the raters, a conversation on verbal and non-verbal expressions of the creation of closeness and distance was stimulated and summarized. Raters were then instructed to watch the videos with the following question: In how far does this individual create closeness to her partner by his or her behavior, by what he/she says or by how hel she says it or in how far does this individual create distance to her partner by his or her behavior, by what he/she says or by how he/she says it? They were asked to concentrate on both verbal and non-verbal signs of creating closeness or distance of one person at a time. For the present study, a continuous rating scale was presented below the videos ranging from -4 (distance), via 0 (neutral), to +4 (closeness). The raters continuously rated the persons attempt to create closeness or distance using the computer mouse. The computer mouse position was recorded four times per second. We aggregated these data to one record per second. As the interrater reliabilities of all three raters were sufficiently high in all conditions (ICC $>0.57$; see Table 2 ) we calculated one mean score (mean created closeness) for each participant in each condition. In addition, we calculated how many seconds participants engaged in creating closeness or distance in each condition (seconds creating closeness/distance) and used the seconds creating closeness variable as a second measurement for the tendency to create closeness. In order to obtain measure of fluctuation for each condition, we used the standard deviation of the closeness/distance rating of one person. In order to eliminate measurement artifacts, we did not take the middle position ( -0.19 to 0.19 ) of the scale into account. For the variable seconds creating closeness, only scores from 0.2 to 4 were included. Analog to this, for the variable seconds creating distance, scores from -0.2 to -4 were counted. For both variables, seconds creating closeness and seconds creating distance, we calculated the total sum of seconds spent creating closeness or distance, respectively. 
Table 2 Demographic, relationship and diagnostic characteristics of participants

\begin{tabular}{|c|c|c|c|c|c|c|}
\hline & \multicolumn{2}{|c|}{$\begin{array}{l}\text { Borderline } \\
(n=30 \text { couples })\end{array}$} & \multicolumn{2}{|c|}{$\begin{array}{l}\text { Healthy control } \\
(n=34 \text { couples })\end{array}$} & \multicolumn{2}{|c|}{$\begin{array}{l}\text { Borderline } \\
\text { vs. control }\end{array}$} \\
\hline & q & $\hat{0}$ & q & 0 & 우 & 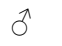 \\
\hline & \multicolumn{2}{|l|}{$M(S D)$} & \multicolumn{2}{|l|}{$M(S D)$} & \multicolumn{2}{|l|}{$p$} \\
\hline Age & $30.1(8.64)$ & $32.4(9.18)$ & $27.4(8.00)$ & $30.9(8.74)$ & .13 & .45 \\
\hline Fluid intelligence & $\begin{array}{l}111 \\
(11.6)\end{array}$ & $\begin{array}{l}109 \\
(14.5)\end{array}$ & $\begin{array}{l}112 \\
(12.7)\end{array}$ & $\begin{array}{l}114 \\
(11.4)\end{array}$ & .72 & .15 \\
\hline School education (years) & $11.47(1.43)$ & $11.47(1.59)$ & $12.15(1.18)$ & $11.47(1.52)$ & $.049 *$ & .99 \\
\hline Relationship length in months & $\begin{array}{l}34.7 \\
(37.9)\end{array}$ & & & $\begin{array}{l}27.9 \\
(27.0)\end{array}$ & .75 & \\
\hline Time spent together (hours per week) & $59.4(34.8)$ & & & $61.2(33.2)$ & .80 & \\
\hline Living together $(\%)^{\mathrm{a}}$ & 52 & & & 63 & .11 & \\
\hline \multirow[t]{2}{*}{ Relationship quality (0-27) } & $18.37(5.07)$ & $17.90(4.48)$ & $20.92(4.34)$ & $20.23(3.41)$ & $.046^{*}$ & $.02 *$ \\
\hline & $\mathrm{n}$ & & $\mathrm{n}$ & & & - \\
\hline \multicolumn{7}{|l|}{ Current axis I disorders ${ }^{\mathrm{b}}$} \\
\hline Mood disorders & 12 & 4 & 0 & 0 & & - \\
\hline Anxiety disorders and OCD & 13 & 3 & 0 & 0 & & - \\
\hline PTSD & 10 & 1 & 0 & 0 & & - \\
\hline Eating disorders & 4 & 0 & 0 & 0 & & - \\
\hline \multicolumn{7}{|l|}{ Substance use disorder ${ }^{c}$} \\
\hline Current axis II disorders & 8 & 6 & 0 & 0 & & - \\
\hline Cluster A PD & 6 & 0 & 0 & 0 & & - \\
\hline Other cluster B PD & 3 & 0 & 0 & 0 & & - \\
\hline Borderline PD & 30 & 1 & 0 & 0 & & - \\
\hline Cluster C PD & 15 & 1 & 0 & 0 & & - \\
\hline Psychotropic medication & $15^{\mathrm{d}}$ & $2^{\mathrm{e}}$ & 0 & 0 & & - \\
\hline
\end{tabular}

o female, ô male, $O C D$ obsessive-compulsive disorder, $P D$ personality disorder, $P T S D$ posttraumatic stress disorder, values are means with standard deviations in parentheses, unless otherwise noted; $p$ values of Mann-Whitney U-tests

$* p<.05$

${ }^{\mathrm{a}} p$ value of chi-square test

${ }^{b}$ Numbers depict individuals with one or more disorders in the respective category

${ }^{c}$ Drug and alcohol addiction and abuse during the past 12 months. Only addicts in current remission with no substance use in the past 3 months were included

${ }^{\mathrm{d}}$ Fifteen were antidepressants, one with additional mood stabilizer, one with additional antipsychotics

${ }^{\mathrm{e} O n e}$ antidepressant, one stimulant

\section{Data Analysis}

Data was analyzed using the Statistical Package for Social Sciences Version 24.0 (SPSS, IBM). Analyses on the support seeking and providing only include data from the fear and the separation condition, as the inter-rater-reliability for the film condition was too low (ICC $<0.40$ ). Data on creating closeness/distance were analyzed with all three conditions as the inter-rater-reliability was sufficiently high. We applied Multi Level Modelling (MLM) for our main analyses. We analyzed men and women separately in all but the threat manipulation check. For the manipulation check, we followed recommendations of West (2013) and treated the dataset as a two-level crossed structure with repeated measure and person being crossed. We used only fixed effects and allowed the error residuals to correlate within dyads and within persons, to account for the within subject and couple structure of our data. Heterogeneous compound symmetry (CSH) was chosen as the applied covariance structure (Kenny et al. 2006), representing the random effects (Quené and Bergh 2004). The BPD and HC groups were analyzed separately. Couples were Level 2 and condition and person were treated as crossed Level 1 variables, results refer to effects on dyad-level. To test our hypotheses (1-5), we analyzed the effect of condition as well as group differences in general, negative and positive support seeking, creating closeness (mean creating closeness and seconds creating closeness), as well as the fluctuation in closeness and negative and positive emotions separately for each gender, 
thus on individual-level. Therefore, we run eight independent MLM, one per outcome. Individuals were treated as the Level 2 variable, with condition as the Level 1 predictor. We conducted MLM with group (to test for Hypotheses 1, 2, 3, \& 5), condition and the Group $x$ Condition interaction (to test for Hypothesis 4), as fixed factors. The separation condition and the $\mathrm{HC}$ group were the reference groups. Also here we applied a CSH covariance structure. If one interaction term (film vs. separation or fear vs. separation) was significant, we report post-hoc t-test analyses with 1000 bootstrap per condition. If the interaction term was not significant, we dropped it from the equation and report main effects without the interaction. The same analytic approach was chosen for our post-hoc tests on group differences in support giving and seconds creating distance. The assumption of normal distribution of error residuals of the MLM predicting seconds creating closeness (Hypotheses 1) and negative emotions (Hypotheses 5) as well as seconds creating distance (post-hoc analyses) was violated, both indicated by Shapiros Wilks (both $W(192)>0.56, p<0.01$ ) and visual inspection. Therefore, we applied non-parametric analyses, using Mann-Whitney U-tests for group differences and rank analysis of covariance to test for differences in emotions after the fear and separation condition, controlling for emotions after the neutral condition (Quade 1967).

As part of our post-hoc analyses, we tested for mutual processes of negative support seeking on negative support giving within the dyad by using Actor-Partner-Interdependence Models (APIM; Kenny et al. 2006). We applied APIMs for the relationship and personally threatening condition and both groups separately, thus 4 models in total. We applied a two-intercept model using MLM (for a thorough description see Kenny 2006, p. 176). With this, actor and partner effects on an outcome can me simultaneously estimated, while accounting for the interdependence between couples. We tested how, separated for both groups, negative support seeking was associated with negative support giving. Predictors were grand mean centered, the outcome was z-standardized. We finally calculated Pearson $r$ correlations between males' and females' variables, except for negative emotions, where we applied Spearman rho correlations. Effect size $r$ is provided. All reported significance values are two-tailed, p-values and regression weights are unadjusted.

\section{Results}

BPD and HC couples did not significantly differ in age, relationship length, weekly hours spent time together or intelligence, but in relationship quality (see Table 2). Mean values, standard deviations and group comparisons (BPD vs. HC) for the dependent variables are depicted in Table 3.

\section{Threat Manipulation Check in Couples}

BPD as well as HC couples reported higher perceived relationship threat after the fear than after the film condition and after the separation than after the fear condition (all $p<0.05$ ). Males and females of the BPD and HC groups also reported higher personal threat after the fear and after the separation condition than after the film condition (all $p<0.001$ ), but no higher personal threat after the separation condition than after the fear condition (both $p>0.51$ ).

\section{Hypotheses 1 and 4: General Support Seeking and Creating Closeness in the Female Sample}

The complete MLMs of the Hypotheses 1, 2, 3, 4 and 5 can be found in the Supplementary Material Tables 1, 2, 3, 4 .

General Support seeking. Predicting general support seeking with a MLM including condition, group and the Group $\mathrm{x}$ Condition $(2 \times 2)$ showed that the interaction was not significant $(b=-0.06, S E=0.16, p=0.28, r=0.04)$. Looking at the main effect, BPD women engaged in significantly more overall $(b=0.41, S E=0.18, p=0.03, r=0.27)$ support seeking.

\section{Mean Creating Closeness}

The Group x Condition $(2 \times 3)$ interaction (film vs. separation) of the MLM predicting mean creating closeness was significant, $b=0.15, S E=0.07, p=0.04, r=0.24$. The interaction Group x Condition (fear vs. separation) was not significant $(b=-0.01, S E=0.07, p=0.85, r=0.02$ ). Independent sample t-tests with 1000 bootstrapped samples per condition revealed that women with BPD showed significantly smaller values in mean creating closeness than $\mathrm{HC}$ women in the fear, $t(47.59)=-3.16, p=0.003, r=0.42$, and in the separation condition, $t(62)=-2.41, p=0.03$, $r=0.29$. The difference in mean creating closeness between BPD females and $\mathrm{HC}$ in the film condition was a nonsignificant trend, $t(62)=-1.92, p=0.06, r=0.24$.

\section{Seconds Creating Closeness}

To test for group differences in seconds creating closeness, we performed three Mann-Whitney-U-tests, one per condition. Women with BPD spent significantly less time creating closeness with their partners than $\mathrm{HC}$ women in the fear condition, $U=658, z=2.02, p=0.044, r=0.25$. The difference between BPD and HC women in the film condition was a nonsignificant trend, $U=634, z=1.69, p=0.09, r=0.21$, and not significant in the separation condition, $U=589$, $z=1.08, p=0.281, r=0.14$; see Fig. 2 . 
Table 3 Mean values, standard deviations and group comparisons of dependent variables

\begin{tabular}{|c|c|c|c|c|c|c|}
\hline \multirow[t]{3}{*}{ Variable } & \multicolumn{2}{|c|}{$\begin{array}{l}\text { Borderline } \\
(N=30 \text { couples })\end{array}$} & \multicolumn{2}{|c|}{$\begin{array}{l}\text { Healthy control } \\
(N=34 \text { couples })\end{array}$} & \multicolumn{2}{|c|}{ Borderline vs. Control } \\
\hline & q & 0 & q & $\hat{0}$ & q & 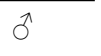 \\
\hline & \multicolumn{2}{|l|}{$M(S D)$} & \multicolumn{2}{|l|}{$M(S D)$} & \multicolumn{2}{|l|}{$p$} \\
\hline \multicolumn{7}{|c|}{ Mean creating closeness (1-9) } \\
\hline Film & $5.83(0.21)$ & $5.84(0.16)$ & $5.93(0.17)$ & $5.89(0.18)$ & $.07 \dagger$ & .18 \\
\hline Fear & $5.66(0.39)$ & $5.76(0.32)$ & $5.92(0.24)$ & $5.85(0.29)$ & $.006 * *$ & .27 \\
\hline Separation & $5.64(0.49)$ & $5.68(0.45)$ & $5.88(0.32)$ & $5.85(0.35)$ & $.03^{*}$ & .11 \\
\hline \multicolumn{7}{|c|}{ Fluctuation between creating closeness and distance $\left(0-0.8^{\mathrm{a}}\right)$} \\
\hline Film & $0.21(0.08)$ & $0.17(0.07)$ & $0.19(0.07)$ & $0.18(0.06)$ & .28 & .62 \\
\hline Fear & $0.31(0.19)$ & $0.27(0.14)$ & $0.22(0.06)$ & $0.21(0.08)$ & $.03 *$ & $.06 \dagger$ \\
\hline Separation & $0.31(0.16)$ & $0.28(0.11)$ & $0.27(0.12)$ & $0.24(0.08)$ & .30 & $.07 \dagger$ \\
\hline \multicolumn{7}{|c|}{ Seconds creating closeness $(0-360)^{\mathrm{b}}$} \\
\hline Film & $341(46.8)$ & $354(19.6)$ & $355(12.0)$ & $351(29.9)$ & $.09 \dagger$ & .64 \\
\hline Fear & $304(79.3)$ & $328(59.5)$ & $344(52.3)$ & $343(39.9)$ & $.04 *$ & .46 \\
\hline Separation & $300(100)$ & $307(97.6)$ & $339(42.5)$ & $340(62.4)$ & .28 & $.04 *$ \\
\hline \multicolumn{7}{|c|}{ Seconds creating distance $(0-360)^{\mathrm{b}}$} \\
\hline Film & $5.70(19.6)$ & $1.17(4.76)$ & $0.84(4.91)$ & $0.82(3.79)$ & .16 & .54 \\
\hline Fear & $27.8(51.2)$ & $14.4(34.3)$ & $7.44(40.6)$ & $5.76(30.5)$ & $.006 * *$ & $.03 *$ \\
\hline Separation & $38.3(78.5)$ & $29.1(77.2)$ & $6.32(19.8)$ & $10.2(51.1)$ & $.05^{*}$ & $.003 * *$ \\
\hline \multicolumn{7}{|c|}{ Overall support seeking (0-7) } \\
\hline Fear & $3.31(0.80)$ & $3.69(0.63)$ & $2.92(0.71)$ & $2.55(0.55)$ & $.04^{*}$ & .36 \\
\hline Separation & $3.61(0.97)$ & $2.74(0.79)$ & $3.17(0.76)$ & $2.68(0.68)$ & $.06 \dagger$ & .75 \\
\hline \multicolumn{7}{|c|}{ Positives support seeking (0-7) } \\
\hline Fear & $2.82(0.78)$ & $2.34(0.64)$ & $2.59(0.76)$ & $2.27(0.56)$ & .21 & .64 \\
\hline Separation & $2.87(.078)$ & $2.31(0.74)$ & $2.81(0.73)$ & $2.37(0.75)$ & .78 & .76 \\
\hline \multicolumn{7}{|c|}{ Negative support seeking $(0-7)$} \\
\hline Fear & $1.54(1.26)$ & $0.84(0.74)$ & $0.66(0.77)$ & $0.43(0.60)$ & $.001 * *$ & .02 \\
\hline Separation & $1.87(1.29)$ & $1.00(0.81)$ & $1.15(0.90)$ & $0.68(0.68)$ & $.02 *$ & .09 \\
\hline \multicolumn{7}{|c|}{ Positive support giving $(0-7)$} \\
\hline Fear & $2.52(0.83)$ & $2.77(0.97)$ & $2.54(0.73)$ & $2.56(0.76)$ & .93 & .35 \\
\hline Separation & $2.36(0.84)$ & $2.53(0.72)$ & $2.48(0.73)$ & $2.36(0.79)$ & .57 & .39 \\
\hline \multicolumn{7}{|c|}{ Negative support giving $(0-7)$} \\
\hline Fear & $1.77(1.24)$ & $1.46(0.96)$ & $1.00(0.90)$ & $0.89(0.77)$ & $.01 *$ & $.01 *$ \\
\hline Separation & $1.63(0.97)$ & $1.52(1.10)$ & $1.02(0.77)$ & $0.92(0.82)$ & $.01 *$ & $.02 *$ \\
\hline \multicolumn{7}{|c|}{ Positive emotions $(1-7)^{\mathrm{b}}$} \\
\hline Film & $2.67(1.08)$ & $3.49(1.34)$ & $3.72(1.23)$ & $4.22(1.17)$ & $.001 * *$ & $.04 *$ \\
\hline Fear & $2.49(1.10)$ & $3.31(1.18)$ & $3.67(1.07)$ & $4.01(1.21)$ & $.001 * *$ & $.04 *$ \\
\hline Separation & $2.94(1.24)$ & $3.97(1.56)$ & $4.36(1.47)$ & $4.92(1.34)$ & $.001 * *$ & $.02 *$ \\
\hline \multicolumn{7}{|c|}{ Negative emotions $(1-7)^{\mathrm{b}}$} \\
\hline Film & $1.85(.95)$ & $1.27(.59)$ & $1.13(.31)$ & $1.20(.35)$ & $.001 * *$ & .79 \\
\hline Fear & $2.89(1.53)$ & $1.66(.92)$ & $1.49(.64)$ & $1.39(.63)$ & $.001 * *$ & $.08 \dagger$ \\
\hline Separation & $3.21(1.53)$ & $1.64(.92)$ & $1.43(.92)$ & $1.32(.64)$ & $.001 * *$ & .17 \\
\hline
\end{tabular}

ㅇ female, $\widehat{\delta}$ male, $H C$ healthy control, $B P D$ borderline personality disorder, $p$-values of t-tests

${ }^{*} p<.05, * * p<.01, \dagger \mathrm{p}<.10$

${ }^{a}$ Maximum of standard deviation in present sample

${ }^{\mathrm{b}} p$-values of Mann-Whitney-U tests

\section{Hypotheses 2 and 4: Negative and Positive Support Seeking}

The two MLM predicting negative and positive support seeking, revealed that the Group x Condition $(2 \times 2)$ interactions were not significant (both $p>0.28$ ). BPD females showed significantly more negative support seeking behaviors $(b=0.82, S E=0.24, p=0.001, r=0.40)$ than $\mathrm{HC}$ women. Female BPD and HC women did not differ 
Table 4 Inter couple correlations (Pearson $r$ and rho) of support seeking, support giving, creating closeness and emotions for all couples $(N=64)$

\begin{tabular}{|c|c|c|c|c|c|c|c|c|c|c|}
\hline & & \multicolumn{9}{|c|}{ Males $(n=64)$} \\
\hline & & 1 & 2 & 3 & 4 & 5 & 6 & 7 & 8 & 9 \\
\hline \multirow{9}{*}{$\begin{array}{l}\text { Females } \\
\qquad(n=64)\end{array}$} & 1 gen. support seeking & .20 & .14 & .13 & -.01 & $.28^{*}$ & .21 & $.34^{*}$ & -.18 & -.16 \\
\hline & 2 pos. support seeking & $.32 *$ & $.36 * *$ & -.15 & $.36 * *$ & .09 & $.45 * *$ & -.02 & $-.28^{*}$ & .07 \\
\hline & 3 neg. support seeking & -.07 & -.18 & $.62 * *$ & $-.60 * *$ & $.51 * *$ & $-.28 *$ & $.74 * *$ & .02 & $-.42 * *$ \\
\hline & 4 creation of closeness & $.29 *$ & $.44 * *$ & $-.54 * *$ & $.78 * *$ & $-.37 * *$ & $.50 * *$ & $-.60 * *$ & $-.26^{*}$ & $.49 * *$ \\
\hline & 5 fluctuation of closeness & .007 & -.08 & $.35 * *$ & $-.41 * *$ & $.60 * *$ & -.14 & $.46^{* *}$ & .04 & $-.28 *$ \\
\hline & 6 pos. support providing & $.41^{*}$ & $.49 * *$ & $-.46 * *$ & $.63 * *$ & $-.24 * *$ & $.49 * *$ & $-.49 * *$ & -.17 & $.35^{* *}$ \\
\hline & 7 neg. support providing & .05 & -.08 & $.70 * *$ & $-.59 * *$ & $.36^{* *}$ & $-.29 * *$ & $.64 * *$ & .09 & $-.39 * *$ \\
\hline & 8 negative emotions & -.23 & $-.32 * *$ & $.25^{*}$ & -.13 & .17 & $-.40 * *$ & $.38 * *$ & $.33 * *$ & $-.38 * *$ \\
\hline & 9 positive emotions & .18 & $.28 *$ & $-.40 * *$ & $.45^{* *}$ & -.19 & $.25^{*}$ & $-.38 * *$ & $-.28 *$ & $.39 * *$ \\
\hline
\end{tabular}

Correlations between females and males scores on dependent variables are shown. Scores were the mean of fear and separation condition. Correlations are Pearson $\mathrm{r}$ correlations except for negative emotions. Here, Spearman rho correlations are reported

$* p<.05, * * p<.01$

in positive support seeking $(b=0.14, S E=0.17, p=0.42$, $r=0.10$; see Fig. 1).

\section{Hypotheses 3 and 4: Fluctuations between Creating Closeness and Distance}

The Group $x$ Condition $(2 \times 3)$ interactions of the MLM predicting fluctuations between creating closeness and distance were insignificant (all $p>0.15, r<0.14$ ). The main effect for group was not significant $(b=0.02, S E=0.02, p=0.25$, $r=0.15$ ). Independent sample t-tests with 1000 bootstrapped samples revealed that BPD women showed significantly more fluctuations between creating closeness and distance than HC women only in the fear condition, $t(34.84)=2.45$, $p=0.025, r=0.38$; see Table 3 .

\section{Hypothesis 5: Positive and Negative Emotions}

Running one Mann-Whitney-U-test per condition for negative emotions revealed that females with BPD showed significantly more negative emotions after the film, the fear and the separation condition (all $p<0.01$ ). Looking at negative emotions after the fear and separation condition, controlling for emotions after the neutral conversation using rank analysis of covariance for negative emotions showed that individuals with BPD experienced significantly more negative emotions after the separation condition (both $\mathrm{p} \leq 0.05$ ), the group difference after the fear condition was a nonsignificant trend $(F$ $\left.(1,62)=3.74, p=0.057, \eta^{2}=0.06\right)$. The MLM predicting positive emotions revealed no significant Group $\mathrm{x}$ Condition $(2 \times 3)$ interactions (both $p>0.11, r<0.17$ ). Women with BPD overall reported fewer positive emotions $(b=-1.12, t=-4.19$, $p<0.01, r=0.47)$.

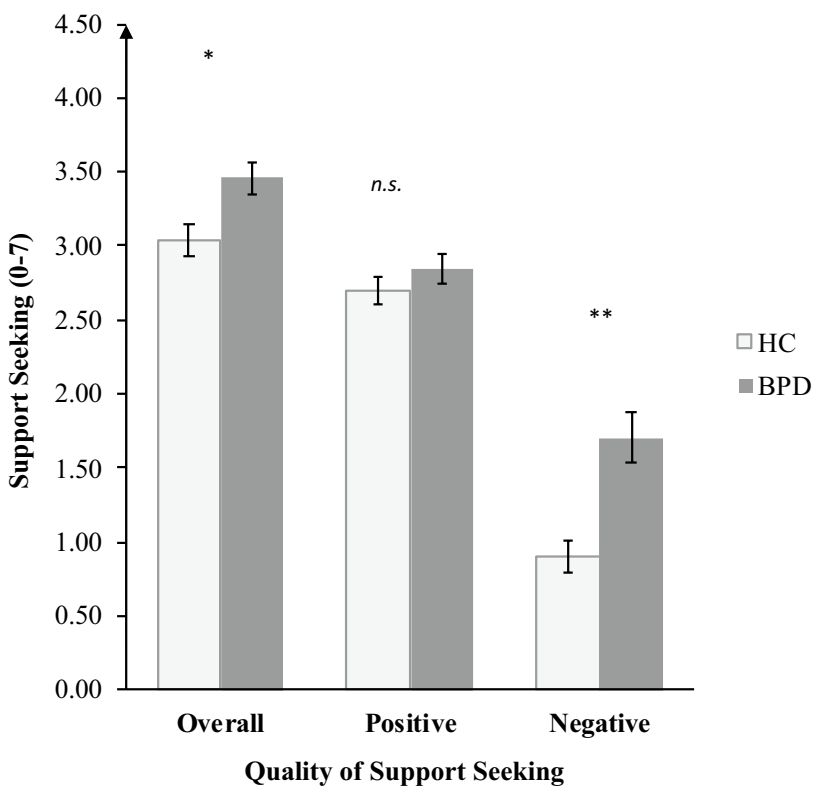

Fig. 1 Comparison of support seeking between BPD and HC women. Bars depict means of support seeking in the fear and separation condition and standard errors of means; Stars indicate significant results from mixed linear models with group and condition as fixed factor. ${ }^{*} p<.05 ; * * p<.01 ; n . s$. non-significant

\section{Post-hoc Analyses}

\section{Seconds Creating Distance}

BPD females spent more time creating distance to their partners than HC women in the fear, $U=363, z=-2.74$, $p=0.006, r=-0.34$, and in the separation condition, $U=392, z=-1.97, p=0.049, r=-0.25$, but not in the 
film condition, $U=454, z=-1.39, p=0.164, r=-17$, as depicted by three Mann-Whitney-U-test; see Fig. 2.

\section{Support Providing in Female Sample}

The Group x Condition $(2 \times 2)$ interactions of the two MLMs predicting negative and positive support providing were both not significant, $p s>0.49$. Women with BPD engaged in more negative support giving, $(b=0.64, S E=0.21, p=0.004$, $r=0.36)$ than HC women, but groups did not differ in positive support giving $(b=-0.07, S E=0.13, p=0.59, r=0.07)$.

\section{Male Sample}

Also for males, the interactions between Group x Condition $(2 \times 2)$ was insignificant in the five MLMs predicting general, positive and negative support seeking and positive and negative support giving ( $p s>0.37)$. Male partners of BPD women engaged in more negative support seeking $(b=0.38$, $S E=0.16, p=0.017, r=0.30)$ and negative support giving $(b=0.58, S E=0.20, p=0.006, r=0.34)$ then HC males. Overall support seeking, as well as positive support seeking and giving did not differ between groups (all $p>0.32$, $r<0.13)$. The Group x Condition $(2 \times 3)$ interactions of mean creating closeness was insignificant as well as the main effect of group (both $\mathrm{p}>0.33, r<0.18$ ). Mann-Whitney U-tests showed that BPD women's partners spent significantly less time creating closeness than $\mathrm{HC}$ women's partners only in the separation condition, $U=663, z=2.07$, $p=0.039, r=0.26$, but not in the film or the fear condition, both $p>0.46$. BPD women's partners spent significantly more time creating distance than $\mathrm{HC}$ women's partners in the fear, $U=401, z=-2.15, p=0.031, r=0.27$, and in the separation condition, $U=331, z=-2.93, p=0.003, r=0.37$, but not in the film condition, $U=533, z=0.61, p=0.54$, $r=0.08$.
The Group x Condition $(2 \times 3)$ interaction film vs. separation of the MLM for fluctuations between creating closeness and distance was significant, $b=-0.05, S E=0.03, \mathrm{p}=0.03$, $r=0.24$, while the interaction for fear vs. separation was not $(b=0.01, S E=0.03, p=0.66, r=0.05)$. Bootstrapped t-tests revealed that BPD women's partners showed significantly more fluctuations between creating closeness and distance than $\mathrm{HC}$ men only in the fear condition, $t(43.04)=2.06$, $p=0.048, r=0.30$. The group difference in the separation condition, $t(52.89)=1.82, p=0.078, r=0.24$, and the film condition, $t(62)=-0.54, p=0.59, r=0.07$ were insignificant.

Male partners did not differ in their negative emotions after all three conversations (all $\mathrm{p}>0.08$; of three Mann-Whitney-U-tests). The Group x Condition $(2 \times 3)$ interactions of the MLM predicting positive emotions were not significant (both $p>0.26, r<0.12$ ). Males of the BPD group experienced overall fewer positive emotions then HC males $(b=-0.71, t=-2.45, p=0.02, r=0.30)$.

\section{Posthoc Analyses on Dyadic Processes}

To make full advantage of the dyadic data structure, we tested how negative support seeking and support providing was associated within couples, looking at the BPD couples and HC couples separately. Finally we looked at the correlations of the variables within couples.

\section{Actor-Partner-Interdependence-Models of Negative Support Seeking and Giving}

To get a better understanding of within couple processes of negative support seeking and giving, we tested how negative support giving was associated with the own persons negative support seeking (actor effect) and with that person's
Fig. 2 Comparison of seconds creating closeness and distance between BPD and HC women. Means and standard error of means are plotted. $H C$ healthy control, $B P D$ borderline personality disorder. Stars depict significant results from MannWhitney-U tests. ${ }^{*} p<.05$; $* * p<.01 ; \dagger p<.10 ;$ n.s. nonsignificant
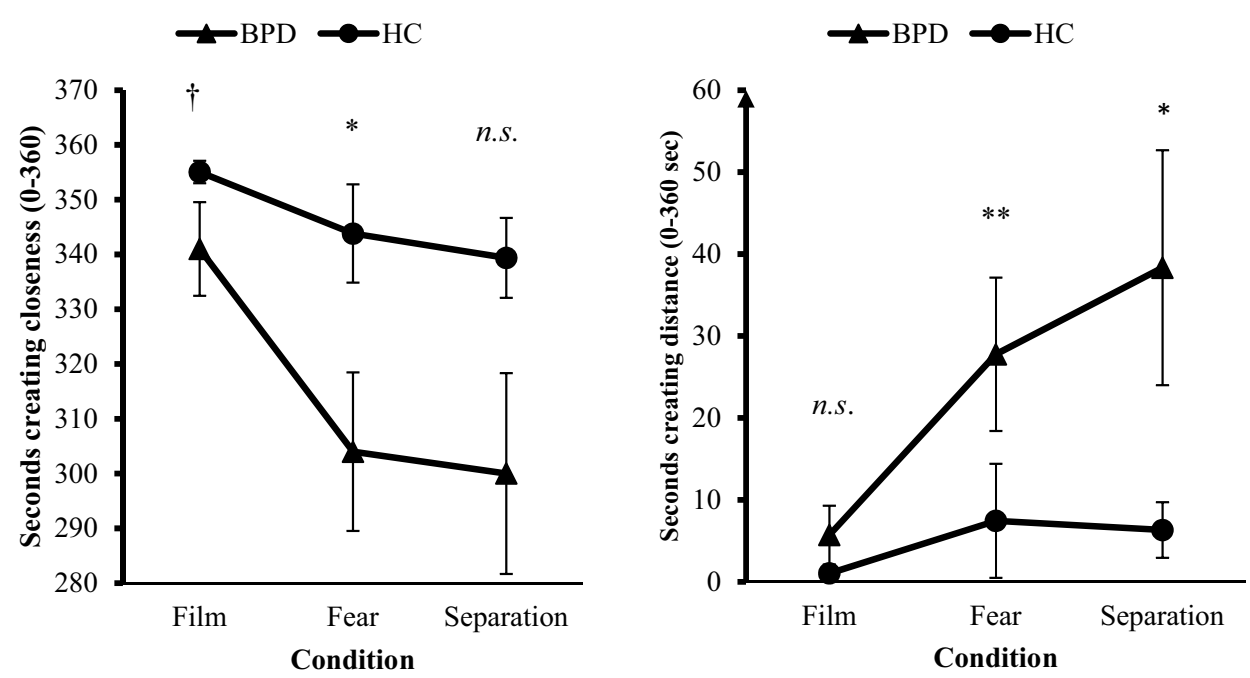
partners support seeking (partner effect) separately for the fear and separation condition. For BPD females, both actor effects of their own negative support seeking on their own negative support giving were significant in the fear and separation condition (both $b>0.56, p<0.001, r>0.76$ ), while the effects of their partners negative support seeking on the BPD persons' negative support giving was insignificant in both conditions (both $b<0.20, p>0.45, r<0.14$ ). For the BPD male partner, the actor effect of negative support seeking on negative support giving was not significant in the fear condition $(b=0.26, S E=0.17, p=0.14, r=0.28)$ and significant in the separation condition $(b=0.43, S E=0.20$, $p=0.04, r=0.38$ ). The effect of BPD participants negative support seeking on BPD males negative support giving were significant (both $b>0.40, p<0.01, r>0.53$ ). In $\mathrm{HC}$ couples, all actor and partner effects of negative support seeking on negative support giving in both conditions were significant (all $b>0.25, p<0.04, \mathrm{r}>0.36$ ), except for one insignificant trend of the partner effect of males' support seeking on females' support giving in the fear condition $(b=0.65$, $S E=0.32, p=0.051, r=0.34)$.

\section{Intercorrelations within Couples}

See Table 4 for correlations of the variables within couples, thus between males and females. Positive support seeking was correlated with positive support providing of the partner (both $r>0.45, p<0.01$ ). Negative support seeking on the other hand was correlated with negative support providing of the partner (both $r>0.70, p<0.001$ ), and with less positive support providing (both $r<-0.28, p<0.05$ ). Fluctuations in the creation of closeness was associated with negative support providing of the partner (both $r>0.35, p<0.01$ ).

\section{Discussion}

With the present study, we examined dyadic ER, i.e., support seeking and the creation of closeness or distance, in a neutral, a personally-threatening and a relationship-threatening conversation of female participants with BPD and HC women with their male partners. Our main findings were that in both threatening situations (a) females with BPD showed more overall and negative support seeking behaviors, and (b) on average, created less closeness to their partners. Furthermore, (c) women with BPD spent less time creating closeness and (d) showed more fluctuations between creating closeness and distance compared to $\mathrm{HC}$ women, both only in the personally-threatening situation. Contrary to our hypotheses, the impact of the personal vs. relationship-threatening situation was not significantly different for women with BPD compared to HC women. Females with BPD felt more negative and less positive after the relationship threatening conversation and less positive after the personally threatening conversation, controlling for emotions after a neutral conversation with their partners. The difference in negative emotions in the personally threatening condition was a nonsignificant trend.

To our knowledge, the present study is the first to examine support seeking and the creation of closeness or distance as means of dyadic ER in females BPD and their male romantic partners. Our results support the assumption that women with BPD show more dyadic ER than HC women when facing emotional or interpersonal problems. In line with research on high levels of interpersonal dependency in BPD (Bornstein et al. 2010), as expected, women with BPD engaged in more overall support seeking than $\mathrm{HC}$ women in both threatening situations. This finding provides empirical support for Linehan's (1993) assumption that individuals with BPD might compensate the inability to regulate their emotions with seeking support by others. At the same time, they were less successful in regulating their emotions, as reflected in less positive and partially more negative emotions after threatening conversations with their partners.

When differentiating between engaging in negative and positive ways of support seeking, we found that women with BPD engaged in more negative support seeking behaviors than $\mathrm{HC}$ women but did not differ from $\mathrm{HC}$ women with regard to positive support seeking. This is in line with prior research showing negative communication patterns in BPD (Bouchard et al. 2009) like expressing more aggression towards one's partner (South et al. 2008; Weinstein et al. 2012), but no general deficits in social competence (Renneberg et al. 2003). In the present study, negative support seeking was conceptualized as behaviors that elicit negative emotions like guilt in the partner and put him under pressure, for example by whining, complaining, attacking or blaming. By performing these behaviors, the women with BPD might elicit stress, anger or annoyance in the potential support provider rather than getting him or her to respond in a helpful, friendly and actually supportive way. Accordingly, more negative support seeking predicted more negative support giving for BPD participants and was correlated with both, more negative and less positive support giving of the partner when looking at the whole sample. Male partners of females with BPD showed more negative forms of support giving than $\mathrm{HC}$ males. Asking for support in a negative way might therefore reflect unsuccessful and ineffective strategies to elicit positive support giving in the partner, potentially reinforcing emotion dysregulation in BPD (Ebner-Priemer et al. 2005; Glenn and Klonsky 2009) and lower levels of relationship satisfaction in individuals with BPD and their partners (Bouchard et al. 2009; South et al. 2008; Stroud et al. 2010). Interestingly, BPD male partners negative support seeking did not significantly predict BPD females' negative support giving. Although both, negative support seeking of BPD 
male partners as well as BPD females' support giving were increased compared to $\mathrm{HCs}$, there was no systematic relationship between the two. Thus, the degree to which BPD females respond with negative ways of support giving might also for their partner be unpredictable.

Although women with BPD were rated to seek more support in both threatening conditions, other than hypothesized, they did not create more closeness to their partners than HC women. In fact, in both threatening conditions BPD women created more distance to their partners than HC women. A possible explanation for the discrepancy between seeking support on the one hand and creating distance on the other hand, could be the presence of an approach withdrawal dilemma in threatening situations (Choi-Kain et al. 2009; Gunderson 1996). Individuals with BPD harbor the tendency of both, high attachment anxiety and avoidance (Agrawal et al. 2004). In stressful or threatening situations, both strategies can be activated at the same time - one triggering approach, the other triggering avoidance, leading to ambivalent and contradicting interpersonal behaviors (Schindler and Sack 2015). Similarly, we showed in a previous analysis on communication behaviors, that women with BPD showed more hostility and less connectedness while simultaneously expressing approaching communication behaviors such as inquiring (Miano et al. 2017c). By sending ambiguous signals, women with BPD might fail to eventually receive their male partner's support.

\section{Fluctuations between Creating Closeness and Distance}

Due to their affective instability, we also expected women with BPD to show more fluctuations between creating closeness and distance in threatening situations than female HC. We could only confirm this hypothesis for the personallythreatening but not for the relationship-threatening situation. Research on relationship threat showed that relationship threat and insecurities can simultaneously activate opposing motivations, i.e., the motivation to protect against expected rejection, which triggers avoidance, and likewise a motivation to restore connection, which triggers approach (Cavallo et al. 2009; Murray et al. 2008; Overall et al. 2014). This might explain why females with BPD and HCs did not differ from each other in fluctuations between creating closeness and distance in the relationship threatening situation.

\section{Male Partner's Dyadic ER}

Interestingly, not only women with BPD and $\mathrm{HC}$ women differed in dyadic ER, but also BPD and HC women's partners. Like their female partners, male partners of BPD women engaged in more negative support seeking and spent more time creating distance and less time creating closeness to their partner than HC men. Additionally, BPD participants' male partners also engaged in more negative support providing than HC women's partners. The fact that BPD women's partners show similar ways of reaching out for dyadic ER as BPD women -i.e. engaging in more negative support seeking while creating more distance and less closeness - could be due to non-random partner-choice processes in individuals with BPD (Bouchard et al. 2009). In a study by Lavner et al. (2015) individuals reporting BPD symptoms tended to be married to partners who also reported more BPD symptoms. Thereby they provided empirical evidence for the hypothesis that individuals with BPD engage in "assortative mating" (Zanarini et al. 2015).

\section{Clinical Implications}

In many intervention programs emotion dysregulation is already a central aspect, however, mostly targeting intrapersonal ER. As proposed before (Fruzzetti and Payne 2015), the results of the present study indicate that in the treatment of BPD, difficulties with dyadic ER should be addressed more directly. That is, interventions should especially focus on (a) reducing over-reliance on dyadic ER, (b) reducing negative ways of support seeking and strengthening the already available repertoire of positive support seeking behaviors, and (c) bringing awareness to potentially conflicting signals individuals with BPD might sent when in need of support. Therapists could explain the discrepancy between asking for support while simultaneously creating distance as well as the possible association between negative support seeking and receiving unhelpful, negative support. Also, individuals with BPD might try to regulate their emotions in patient-therapist situation similarly as in the dyadic relationship with their partner. Hence, for the therapist-patient relationship it is important to understand that by showing negative support seeking and ambivalent approach withdrawal behavior, individuals with BPD might signal to need support.

\section{Limitations and Future Directions}

While our study has contributed to a better understanding of difficulties in dyadic ER in romantic relationships in BPD, several qualities of this research limit the interpretations that can be drawn from the results. First, we cannot confirm the specificity of our results for BPD as we did not include a clinical control sample, also generalizability of our results to males with $\mathrm{BPD}$, non-heterosexual relationships and other relationship statuses is limited, since we only included female individuals with BPD that are currently in a relationship to a male partner, but not married to him. The neutral baseline condition was not suitable to 
receive reliable observation measures of most of the constructs, showing that the measure was arbitrary for situations in which no support seeking was shown. Therefore, another neutral conversation that does elicit some support seeking (i.e., solving an uncritical problem), would have been better suitable. Also, measures of support seeking and providing were global, mean measures, summarizing how each partner behaved across the entire 6 min conversations. Future studies could make use of behavioral microanalyses that allow for the continuous rating of interactions (i.e., Gordon and Feldman 2008). Additionally, in the present study we only examined dyadic ER on a behavioral level. Future studies could include psychophysiological markers to measure stress, outside participants awareness to better understand the regulatory effectivity of these behaviors in BPD and their communication partners. We also are unaware of the participants actual ability of support giving abilities. Thus, the quantity and quality of support seeking might be influenced by prior experiences of the support giving quality of the partner. Future studies should assess support giving abilities by self-report measures (Hofmann et al. 2016; Niven et al. 2011) or standardized tests. Finally, dyadic ER can not only be examined by support seeking and providing and the creation of closeness or distance, but also, for example, via co-regulation (Butler and Randall 2012) or co-reappraisal (Horn and Maercker 2016). Hence, other ways of dyadic ER in BPD should be examined to extend the knowledge about possible impairments in dyadic ER in BPD.

\section{Conclusions}

Our study indicates that women with BPD have impairments in dyadic ER and are less able to sucessfully regulate their emotions in threatening conversations with their partner. In threatening situations, women with BPD displayed increased overall and negative support seeking while simultaneously creating distance to the potential support provider, their partner. Increased overall and negative support seeking and simultaneously distancing from the partner might reflect the use of ineffective and contradictory dyadic ER strategies. Our findings provide possible explanations for romantic relationship dysfunctions often seen in BPD and highlight the importance of implementing dyadic ER strategies into the treatment of BPD. Further research on the emotion regulatory effects of these behaviors, as well as on the specificity of our findings to BPD and the generalizability to other forms of dyads is needed.

Supplementary Information The online version of this article (https:// doi.org/10.1007/s10608-021-10206-8) contains supplementary material, which is available to authorized users.
Funding Open Access funding enabled and organized by Projekt DEAL. This study was supported by the Research Cluster Languages of Emotion of the Freie Universität Berlin, as part of the German Excellence Initiative funded by the German Research Foundation. The manuscript was written at the Department of Clinical Psychology and Psychotherapy, Heidelberg University.

\section{Compliance with Ethical Standards}

Conflict of Interest Annemarie Miano, Sven Barnow, Stina Wagner, Stefan Roepke, and Isabel Dziobek declare that they have no conflict of interest.

Ethical Approval The study was approved by a local ethics committee. All procedures performed in studies involving human participants were in accordance with the ethical standards of the institutional research committee and with the 1964 Helsinki declaration and its later amendments or comparable ethical standards.

Animal Rights No animal studies were carried out by the authors for this article.

Informed Consent Informed consent was obtained from all individual participants included in the study.

Open Access This article is licensed under a Creative Commons Attribution 4.0 International License, which permits use, sharing, adaptation, distribution and reproduction in any medium or format, as long as you give appropriate credit to the original author(s) and the source, provide a link to the Creative Commons licence, and indicate if changes were made. The images or other third party material in this article are included in the article's Creative Commons licence, unless indicated otherwise in a credit line to the material. If material is not included in the article's Creative Commons licence and your intended use is not permitted by statutory regulation or exceeds the permitted use, you will need to obtain permission directly from the copyright holder. To view a copy of this licence, visit http://creativecommons.org/licenses/by/4.0/.

\section{References}

Agrawal, H., Gunderson, J., Holmes, B., \& Lyons-Ruth, K. (2004). Attachment studies with borderline patients: A review. Harvard Review of Psychiatry, 12, 94-104. https://doi.org/10.1080/10673 220490447218.

American Psychiatric Association. (2013). Diagnostic and statistical manual of mental disorders (DSM-5®). Washington, D. C. : American Psychiatric Pub. https://doi.org/10.1176/appi.books .9780890425596.x00diagnosticclassification.

Barnow, S., Limberg, A., Stopsack, M., Spitzer, C., Grabe, H., Freyberger, H., \& Hamm, A. (2012). Dissociation and emotion regulation in borderline personality disorder. Psychological Medicine, 42(4), 783-794. https://doi.org/10.1017/s0033291711001917.

Barnow, S., Stopsack, M., Grabe, H. J., Meinke, C., Spitzer, C., Kronmüller, K., \& Sieswerda, S. (2009). Interpersonal evaluation bias in borderline personality disorder. Behaviour Research and Therapy, 47(5), 359-365. https://doi.org/10.1016/j.brat.2009.02.003.

Baucom, K. J., Baucom, B. R., \& Christensen, A. (2012). Do the naïve know best? The predictive power of naïve ratings of couple interactions. Psychological Assessment, 24(4), 983. https://doi. org/10.1037/a0028680. 
Beck, A. T., Freeman, A., \& Davis, D. D. (Eds.). (2004). Cognitive therapy of personality disorders (2nd ed.). New York: Guilford Press.

Beeney, J. E., Hallquist, M. N., Clifton, A. D., Lazarus, S. A., \& Pilkonis, P. A. (2018). Social disadvantage and borderline personality disorder: A study of social networks. Personality Disorders Theory, Research, and Treatment, 9(1), 62. https://doi. org/10.1037/per0000234.

Beeney, J. E., Hallquist, M. N., Scott, L. N., Ringwald, W. R., Stepp, S. D., Lazarus, S. A., \& Pilkonis, P. A. (2019). The emotional bank account and the four horsemen of the apocalypse in romantic relationships of people with borderline personality disorder: A dyadic observational study. Clinical Psychological Science, 7(5), 1063-1077. https://doi.org/10.1177/2167702619830647.

Berenson, K. R., Gregory, W. E., Glaser, E., Romirowsky, A., Rafaeli, E., Yang, X., \& Downey, G. (2016). Impulsivity, rejection sensitivity, and reactions to stressors in borderline personality disorder. Cognitive Therapy and Research, 40(4), 510-521. https://doi. org/10.1007/s10608-015-9752-y.

Bolwby, J. (1969). Attachment and loss: Vol. 1. Attachment. New York: Basic Books.

Bornstein, R. F., Becker-Matero, N., Winarick, D. J., \& Reichman, A. L. (2010). Interpersonal dependency in borderline personality disorder: Clinical context and empirical evidence. Journal of Personality Disorders, 24(1), 109-127. https://doi.org/10.1521/ pedi.2010.24.1.109.

Bouchard, S., Sabourin, S., Lussier, Y., \& Villeneuve, E. (2009). Relationship quality and stability in couples when one partner suffers from borderline personality disorder. Journal of Marital and Family Therapy, 35(4), 446-455. https://doi.org/10.111 1/j.1752-0606.2009.00151.x.

Butler, E. A., \& Randall, A. K. (2012). Emotional coregulation in close relationships. Emotion Review. https://doi.org/10.1177/17540 73912451630

Cavallo, J. V., Fitzsimons, G. M., \& Holmes, J. G. (2009). Taking chances in the face of threat: Romantic risk regulation and approach motivation. Personality and Social Psychology Bulletin. https://doi.org/10.1177/0146167209332742.

Choi-Kain, L. W., Fitzmaurice, G. M., Zanarini, M. C., Laverdière, O., \& Gunderson, J. G. (2009). The relationship between selfreported attachment styles, interpersonal dysfunction, and borderline personality disorder. The Journal of Nervous and Mental Disease, 197(11), 816-821. https://doi.org/10.1097/nmd.0b013 e3181bea56e.

Coan, J. A., Schaefer, H. S., \& Davidson, R. J. (2006). Lending a hand: Social regulation of the neural response to threat. Psychological Science, 17(12), 1032-1039. https://doi.org/10.111 1/j.1467-9280.2006.01832.x.

Cogswell, A., \& Alloy, L. B. (2006). The relation of neediness and axis II pathology. Journal of Personality Disorders, 20(1), 16-21. https ://doi.org/10.1521/pedi.2006.20.1.16.

Collins, N. L., \& Feeney, B. C. (2000). A safe haven: an attachment theory perspective on support seeking and caregiving in intimate relationships. Journal of Personality and Social Psychology, 78(6), 1053. https://doi.org/10.1037/0022-3514.78.6.1053.

Collins, N. L., \& Feeney, B. C. (2004). Working models of attachment shape perceptions of social support: Evidence from experimental and observational studies. Journal of Personality and Social Psychology, 87(3), 363. https://doi.org/10.1037/0022-3514.87.3.363.

Collins, N. L., \& Ford, M. B. (2010). Responding to the needs of others: The caregiving behavioral system in intimate relationships. Journal of Social and Personal Relationships, 27(2), 235-244. https://doi.org/10.1177/0265407509360907.

Conklin, C. Z., Bradley, R., \& Westen, D. (2006). Affect regulation in borderline personality disorder. The Journal of Nervous and
Mental Disease, 194(2), 69-77. https://doi.org/10.1097/01. nmd.0000198138.41709.4f.

Dakof, G. A., \& Taylor, S. E. (1990). Victims' perceptions of social support: what is helpful from whom? Journal of Personality and Social Psychology, 58(1), 80. https://doi. org/10.1037/0022-3514.58.1.80.

Daros, A. R., \& Williams, G. E. (2019). A Meta-analysis and systematic review of emotion-regulation strategies in borderline personality disorder. Harvard Review of Psychiatry, 27(4), 217-232. https://doi.org/10.1097/hrp.0000000000000212.

Dixon-Gordon, K. L., Haliczer, L. A., Conkey, L. C., \& Whalen, D. J. (2018). Difficulties in interpersonal emotion regulation: Initial development and validation of a self-report measure. Journal of Psychopathology and Behavioral Assessment, 40(3), 528-549. https://doi.org/10.1007/s10862-018-9647-9.

Donegan, N. H., Sanislow, C. A., Blumberg, H. P., Fulbright, R. K., Lacadie, C., Skudlarski, P., \& Wexler, B. E. (2003). Amygdala hyperreactivity in borderline personality disorder: Implications for emotional dysregulation. Biological Psychiatry, 54(11), 1284 1293. https://doi.org/10.1016/S0006-3223(03)00636-X.

Ebner-Priemer, U. W., Badeck, S., Beckmann, C., Wagner, A., Feige, B., Weiss, I., \& Bohus, M. (2005). Affective dysregulation and dissociative experience in female patients with borderline personality disorder: A startle response study. Journal of Psychiatric Research, 39(1), 85-92. https://doi.org/10.1016/j.jpsychires .2004.05.001.

Ebner-Priemer, U. W., Kuo, J., Kleindienst, N., Welch, S. S., Reisch, T., Reinhard, I., \& Bohus, M. (2007). State affective instability in borderline personality disorder assessed by ambulatory monitoring. Psychological Medicine, 37(7), 961-970. https://doi. org/10.1017/s0033291706009706.

Fineberg, S. K., Leavitt, J., Landry, C. D., Neustadter, E. S., Lesser, R. E., Stahl, D. S., \& Corlett, P. R. J. P. (2018). Individuals with borderline personality disorder show larger preferred social distance in live dyadic interactions. Psychiatry Research, 260, 384-390. https://doi.org/10.1016/j.psychres.2017.11.054.

Fonagy, P., \& Bateman, A. (2008). The development of borderline personality disorder - a mentalizing model. Journal of Personality Disorders, 22(1), 4-21. https://doi.org/10.1521/pedi.2008.22.1.4.

Fruzzetti, A. (2006). The high-conflict couple: A dialectical behavior therapy guide to finding peace, intimacy, and validation. Oakland: New Harbinger Publications.

Fruzzetti, A., \& Payne, L. (2015). Couple therapy and borderline personality disorder. In A. S. Gurman, J. L. Lebow, D. K. Snyder, A. S. Gurman, J. L. Lebow, \& D. K. Snyder (Eds.), Clinical handbook of couple therapy (5th ed., pp. 606-634). New York, NY, US: Guilford Press.

Glenn, C. R., \& Klonsky, E. D. (2009). Emotion dysregulation as a core feature of borderline personality disorder. Journal of Personality Disorders, 23(1), 20-28. https://doi.org/10.1521/ pedi.2009.23.1.20.

Goodman, M., Carpenter, D., Tang, C. Y., Goldstein, K. E., Avedon, J., Fernandez, N., \& Triebwasser, J. (2014). Dialectical behavior therapy alters emotion regulation and amygdala activity in patients with borderline personality disorder. Journal of Psychiatric Research, 57, 108-116. https://doi.org/10.1016/j.jpsychires .2014.06.020.

Gordon, I., \& Feldman, R. (2008). Synchrony in the triad: A microlevel process model of coparenting and parent-child interactions. Family Process, 47(4), 465-479. https://doi.org/10.111 1/j.1545-5300.2008.00266.x.

Gratz, K. L., \& Roemer, L. (2008). "Multidimensional assessment of emotion regulation and dysregulation: Development, factor structure, and initial validation of the difficulties in emotion regulation scale": Erratum. Journal of Psychopathology and 
Behavioral Assessment, 30(4), 315-315. https://doi.org/10.1007/ s10862-008-9102-4.

Grilo, C. M., Sanislow, C. A., Skodol, A. E., Gunderson, J. G., Stout, R. L., Bender, D. S., \& Zanarini, M. C. (2007). Longitudinal diagnostic efficiency of DSM-IV criteria for borderline personality disorder: A 2-year prospective study. The Canadian Journal of Psychiatry, 52(6), 357-362. https://doi.org/10.1177/0706743707 05200604 .

Gross, J. J. (1998). Antecedent- and response-focused emotion regulation: Divergent consequences for experience, expression, and physiology. Journal of Personality and Social Psychology, 74(1), 224-237. https://doi.org/10.1037/0022-3514.74.1.224.

Gross, J. J., Richards, J. M., \& John, O. P. (2006). Emotion regulation in everyday life. In D. K. Snyder, J. Simpson, J. N. Hughes, D. K. Snyder, J. Simpson, \& J. N. Hughes (Eds.), Emotion regulation in couples and families: Pathways to dysfunction and health (pp. 13-35). Washington, DC, US: American Psychological Association.

Gunderson, J. G. (1996). The borderline patient's intolerance of aloneness: Insecure attachments and therapist availability. American Journal of Psychiatry, 153(6), 752-758. https://doi.org/10.1176/ ajp.153.6.752.

Gunderson, J. G. (2007). Disturbed relationships as a phenotype for borderline personality disorder. American Journal of Psychiatry, 164(11), 1637-1640. https://doi.org/10.1176/appi. ajp.2007.07071125.

Gurung, R., Sarason, B., \& Sarason, I. (1997). Close personal relationships and health outcomes: A key to the role of social support. In S. Duck (Ed.), Handbook of personal relationships: Theory, research and interventions (pp. 547-573). Chichester: Wiley.

Hall, J. A., \& Baym, N. K. (2012). Calling and texting (too much): Mobile maintenance expectations, (over) dependence, entrapment, and friendship satisfaction. New Media and Society, 14(2), 316-331. https://doi.org/10.1177/1461444811415047.

Hofmann, S. G. (2014). Interpersonal emotion regulation model of mood and anxiety disorders. Cognitive Therapy and Research, 38(5), 483-492. https://doi.org/10.1002/da.21888.

Hofmann, S. G., Carpenter, J. K., \& Curtiss, J. (2016). Interpersonal emotion regulation questionnaire (IERQ): Scale development and psychometric characteristics. Cognitive Therapy and Research, 40(3), 341-356. https://doi.org/10.1007/s10608-016-9756-2.

Horn, A. B., \& Maercker, A. (2016). Intra- and interpersonal emotion regulation and adjustment symptoms in couples: The role of co-brooding and co-reappraisal. BMC Psychology. https://doi. org/10.1186/s40359-016-0159-7.

Horn, W. (1983). Leistungsprüfungssystem (LPS) [Performance assessment system]. Handanweisung für die Durchführung. Auswertung und Interpretation [Handbook of Procedure, Analysis and Interpretation], 2, 36-37.

Houben, M., Claes, L., Sleuwaegen, E., Berens, A., \& Vansteelandt, K. (2018). Emotional reactivity to appraisals in patients with a borderline personality disorder: A daily life study. Borderline Personality Disorder and Emotion Dysregulation, 5(1), 18. https:// doi.org/10.1186/s40479-018-0095-7.

Houben, M., Vansteelandt, K., Claes, L., Sienaert, P., Berens, A., Sleuwaegen, E., \& Kuppens, P. (2016). Emotional switching in borderline personality disorder: A daily life study. Personality Disorders Theory, Research, and Treatment, 7(1), 50. https://doi. org/10.1037/per0000126.

Julien, D., \& Markman, H. J. (1991). Social support and social networks as determinants of individual and marital outcomes. Journal of Social and Personal Relationships, 8(4), 549-568. https:// doi.org/10.1177/026540759184006.

Kenny, D. A., Kashy, D. A., \& Cook, W. L. (2006). Dyadic data analysis. New York USA: Guilford Press.
Kliem, S., Job, A.-K., Kröger, C., Bodenmann, G., Stöbel-Richter, Y., Hahlweg, K., \& Brähler, E. (2012). Entwicklung und Normierung einer Kurzform des Partnerschaftsfragebogens (PFB-K) an einer repräsentativen deutschen Stichprobe. Zeitschrift für Klinische Psychologie und Psychotherapie, 41(2), 81-89. https://doi. org/10.1026/1616-3443/a000135.

Lavner, J. A., Lamkin, J., \& Miller, J. D. (2015). Borderline personality disorder symptoms and newlyweds' observed communication, partner characteristics, and longitudinal marital outcomes. Journal of Abnormal Psychology, 124(4), 975-981. https://doi. org/10.1037/abn0000095.

Levy, K. N. (2005). The implications of attachment theory and research for understanding borderline personality disorder. Development and Psychopathology, 17(4), 959. https://doi.org/10.1017/s0954 579405050455.

Levy, K. N., Edell, W. S., \& McGlashan, T. H. (2007). Depressive experiences in inpatients with borderline personality disorder. Psychiatric Quarterly, 78(2), 129-143. https://doi.org/10.1007/ s11126-006-9033-8.

Lieb, K., Zanarini, M. C., Schmahl, C., Linehan, M. M., \& Bohus, M. (2004). Borderline personality disorder. The Lancet, 364(9432), 453-461. https://doi.org/10.1016/s0140-6736(04)16770-6.

Limberg, A., Barnow, S., Freyberger, H. J., \& Hamm, A. O. (2011). Emotional vulnerability in borderline personality disorder is cue specific and modulated by traumatization. Biological Psychiatry, 69(6), 574-582. https://doi.org/10.1016/j.biopsych.2010.10.024.

Linehan, M. (1993). Cognitive-behavioral treatment of borderline personality disorder. New York, USA: Guilford Press.

Miano, A., Dziobek, I., \& Roepke, S. (2017a). Understanding interpersonal dysfunction in borderline personality disorder: A naturalistic dyadic study reveals absence of relationship-protective empathic inaccuracy. Clinical Psychological Science, 5(2), 355-366. https ://doi.org/10.1177/2167702616683505.

Miano, A., Dziobek, I., \& Roepke, S. (2020). Characterizing couple dysfunction in borderline personality disorder. Journal of Personality Disorders, 34(2), 181-198. https://doi.org/10.1521/ pedi_2018_32_388.

Miano, A., Fertuck, E. A., Roepke, S., \& Dziobek, I. (2017b). Romantic relationship dysfunction in borderline personality disorder-a naturalistic approach to trustworthiness perception. Personality Disorders Theory, Research, and Treatment. https://doi. org/10.1037/per0000196.

Miano, A., Grosselli, L., Roepke, S., \& Dziobek, I. (2017c). Emotional dysregulation in borderline personality disorder and its influence on communication behavior and feelings in romantic relationships. Behaviour Research and Therapy, 95, 148-157. https:// doi.org/10.1016/j.brat.2017.06.002.

Mikulincer, M., Gillath, O., \& Shaver, P. R. (2002). Activation of the attachment system in adulthood: threat-related primes increase the accessibility of mental representations of attachment figures. Journal of Personality and Social Psychology, 83(4), 881-895. https://doi.org/10.1037/0022-3514.83.4.881.

Murray, S. L., Derrick, J. L., Leder, S., \& Holmes, J. G. (2008). Balancing connectedness and self-protection goals in close relationships: A levels-of-processing perspective on risk regulation. Journal of Personality and Social Psychology, 94(3), 429. https://doi. org/10.1037/0022-3514.94.3.429.

Niven, K., Totterdell, P., Stride, C., \& Holman, D. (2011). Emotion regulation of others and self (EROS): The development and validation of a new individual difference measure. Current Psychology, 30(1), 53-73. https://doi.org/10.1007/s12144-011-9099-9.

Overall, N. C., Girme, Y. U., Lemay, E. P., Jr., \& Hammond, M. D. (2014). Attachment anxiety and reactions to relationship threat: The benefits and costs of inducing guilt in romantic partners. Journal of Personality and Social Psychology, 106(2), 235. https ://doi.org/10.1037/a0034371. 
Pasch, L. A., Harris, K. W., Sullivan, K. T., \& Bradbury, T. N. (2004). The social support interaction coding system. In D. B. P. Kerig (Ed.), Couple observational coding systems (pp. 319-334). New York: Guilford Press.

Perry, J. C., \& Klerman, G. L. (1978). The borderline patient: A comparative analysis of four sets of diagnostic criteria. Archives of General Psychiatry, 35(2), 141-150. https://doi.org/10.1001/archp syc.1978.01770260019001.

Pierce, G. R., Sarason, B. R., Sarason, I. G., Joseph, H. J., \& Henderson, C. A. (1996). Conceptualizing and assessing social support in the context of the family. Handbook of social support and the family (pp. 3-23). New York, USA: Springer.

Quené, H., \& Van den Bergh, H. (2004). On multi-level modeling of data from repeated measures designs: A tutorial. Speech communication, 43(1-2), 103-121. https://doi.org/10.1016/j.speco m.2004.02.004.

Quade, D. (1967). Rank analysis of covariance. Journal of the American Statistical Association, 62(320), 1187-1200. https://doi. org/10.1080/01621459.1967.10500925.

Renneberg, B., Mücke, M., Wallis, H., Fydrich, T., \& Thomas, C. (2003). Wie sozial kompetent sind Patientinnen mit Borderline Persönlichkeitsstörung. Verhaltenstherapie und Verhaltensmedizin, 24(3), 329-345.

Ritter, K., Vater, A., Rüsch, N., Schröder-Abé, M., Schütz, A., Fydrich, T., \& Roepke, S. (2014). Shame in patients with narcissistic personality disorder. Psychiatry Research, 215(2), 429-437. https:// doi.org/10.1016/j.psychres.2013.11.019.

Sauer, C., Sheppes, G., Lackner, H. K., Arens, E. A., Tarrasch, R., \& Barnow, S. (2016). Emotion regulation choice in female patients with borderline personality disorder: Findings from self-reports and experimental measures. Psychiatry Research, 242, 375-384. https://doi.org/10.1016/j.psychres.2016.04.113.

Schienle, A., Wabnegger, A., Schöngassner, F., \& Leutgeb, V. (2015). Effects of personal space intrusion in affective contexts: An fMRI investigation with women suffering from borderline personality disorder. Social Cognitive and Affective Neuroscience, 10(10), 1424-1428. https://doi.org/10.1093/scan/nsv034.

Schindler, A., \& Sack, P.-M. (2015). Exploring attachment patterns in patients with comorbid borderline personality and substance use disorders. The Journal of Nervous and Mental Disease, 203(11), 820-826. https://doi.org/10.1097/nmd.0000000000000377.

Sheehan, D. V., Lecrubier, Y., Sheehan, K. H., Amorim, P., Janavs, J., Weiller, E., \& Dunbar, G. C. (1998). The Mini-international neuropsychiatric interview (MINI): The development and validation of a structured diagnostic psychiatric interview for DSM-IV and ICD-10. Journal of Clinical Psychiatry, 59, 22-33. https://doi. org/10.1016/s0924-9338(97)83297-x.

Simpson, J. A., Rholes, W. S., \& Nelligan, J. S. (1992). Support seeking and support giving within couples in an anxietyprovoking situation: The role of attachment styles. Journal of Personality and Social Psychology, 62(3), 434. https://doi. org/10.1037/0022-3514.62.3.434.

Simpson, J. A., Rholes, W. S., Oriña, M. M., \& Grich, J. (2002). Working models of attachment, support giving, and support seeking in a stressful situation. Personality and Social Psychology Bulletin, 28(5), 598-608. https://doi.org/10.1177/0146167202288004.

South, S. C., Turkheimer, E., \& Oltmanns, T. F. (2008). Personality disorder symptoms and marital functioning. Journal of Consulting and Clinical Psychology, 76(5), 769. https://doi.org/10.1037/ a0013346.

Staebler, K., Helbing, E., Rosenbach, C., \& Renneberg, B. (2011). Rejection sensitivity and borderline personality disorder. Clinical Psychology and Psychotherapy, 18(4), 275-283. https://doi. org/10.1002/cpp.705.

Stanley, B., \& Siever, L. J. (2010). The interpersonal dimension of borderline personality disorder: Toward a neuropeptide model. American Journal of Psychiatry, 167(1), 24-39. https://doi. org/10.1176/appi.ajp.2009.09050744.

Stroud, C. B., Durbin, C. E., Saigal, S. D., \& Knobloch-Fedders, L. M. (2010). Normal and abnormal personality traits are associated with marital satisfaction for both men and women: An actor-partner interdependence model analysis. Journal of Research in Personality, 44(4), 466-477. https://doi.org/10.1016/j. jrp.2010.05.011.

Verhofstadt, L. L., Lemmens, G., \& Buysse, A. (2013). Support-seeking, support-provision and support-perception in distressed married couples: A multi-method analysis. Journal of Family Therapy, 35(3), 320-339. https://doi.org/10.1111/1467-6427.12001.

Weinstein, Y., Gleason, M. E., \& Oltmanns, T. F. (2012). Borderline but not antisocial personality disorder symptoms are related to self-reported partner aggression in late middle-age. Journal of Abnormal Psychology, 121(3), 692. https://doi.org/10.1037/a0028 994.

West, T. V. (2013). Repeated-measure methods with dyads. The Oxford handbook of close relationships (pp. 731-749). Oxford: Oxford University Press.

Westen, D., Moses, M. J., Silk, K. R., Lohr, N. E., Cohen, R., \& Segal, H. (1992). Quality of depressive experience in borderline personality disorder and major depression: When depression is not just depression. Journal of Personality Disorders, 6(4), 382-393. https ://doi.org/10.1521/pedi.1992.6.4.382.

Zaki, J., \& Williams, W. C. (2013). Interpersonal emotion regulation. Emotion, 13(5), 803. https://doi.org/10.1037/a0033839.

Zanarini, M. C., Frankenburg, F. R., Reich, D. B., Wedig, M. M., Conkey, L. C., \& Fitzmaurice, G. M. (2015). The course of marriage/ sustained cohabitation and parenthood among borderline patients followed prospectively for 16 years. Journal of Personality Disorders, 29(1), 62-70. https://doi.org/10.1521/pedi_2014_28_147.

Zimmerman, M., Multach, M. D., Dalrymple, K., \& Chelminski, I. (2017). Clinically useful screen for borderline personality disorder in psychiatric out-patients. The British Journal of Psychiatry, 210(2), 165-166. https://doi.org/10.1192/bjp.bp.116.182121.

Publisher's Note Springer Nature remains neutral with regard to jurisdictional claims in published maps and institutional affiliations. 